\title{
Study on the north-east monsoon onset features using a ground-based microwave radiometer over SHAR
}

\author{
R Pushpa Saroja ${ }^{1, *}$, M Rajasekhar ${ }^{1}, \mathrm{G}_{\text {Papa }} \mathrm{RAO}^{1}, \mathrm{~S}^{\mathrm{Rambabu}}{ }^{1}$, \\ A K GHosh ${ }^{1}$ and G Bharathi ${ }^{2}$ \\ ${ }^{1}$ Meteorology Facility, SDSC SHAR, Sriharikota, Andhra Pradesh, India. \\ ${ }^{2}$ Department of Meteorology and Oceanography, Andhra University, Visakhapatnam, Andhra Pradesh, India. \\ ${ }^{*}$ Corresponding author.e-mail: pushpamet@gmail.com
}

MS received 17 November 2018; revised 20 March 2019; accepted 22 May 2019

Convection has a significant role in maintaining the atmospheric dynamics and thermodynamics; particularly in the tropical regions, it can often lead to the formation of clouds and precipitation, release of latent heat, etc. Microwave radiometers (MWRs) have evolved as a powerful tool for monitoring the genesis and evolution of the convection over a site. Ground-based MWRs are installed at the Satish Dhawan Space Centre SHAR, (SDSC SHAR) Sriharikota $\left(13.72^{\circ} \mathrm{N} ; 8^{\circ} .18^{\circ} \mathrm{E}\right)$ located over south coastal Andhra Pradesh, the south-east coast of India in 2014. MWR provides high temporal resolution vertical profiles of temperature, vapour density and liquid column measurements. The mean profiles of temperature and vapour density of upper-air ascents of GPS radiosonde and microwave radiometer (MWR) are compared for the same location. After the middle of October, the rainfall pattern over south peninsular India and in particular Tamil Nadu and south coastal Andhra Pradesh is due to the arrival of the northeasterly/easterly winds. The aim of the present study is to use MWR products for the north-east monsoon (NEM) onset study. In addition to the European Centre for Medium-Range Weather Forecasts (ECMWF) and operational WRF models, reanalysis data products were also used for the study. The association between the temporal evaluation of thermodynamic profiles and NEM onset has been tested for 3 years. The present results suggest that during the period of NEM onset, $3-5$ days early signatures can be observed by MWR.

Keywords. Microwave radiometer; north-east monsoon; precipitable water; remote sensing.

\section{Introduction}

The advantage of high temporal measurements of atmospheric profiling through ground-based remote sensing has made it a crucial input for weather nowcasting and forecasting areas from the past few years. Several studies have addressed the characterisation of the temperature in the troposphere using microwave radiometer (MWR) measurements (Basili et al. 2001; Löhnert and Maier 2012). Due to its high temporal resolution Published online: 25 July 2019 measurements, MWR is used for boundary-layer studies in many meteorological centres. Earlier we used to rely only on conventional methods like radiosonde observations for understanding the thermodynamical state of the atmosphere; in the later stage, numerical weather prediction models came into existence for forecasting (Kasahara 1961; Ooyama 1964; Anthes 1971). With the progression of remote sensing tools in weather and climate, it has become much easier to know the present state with passive instruments like ground-based 
MWRs. Some of the applications of MWR include nowcasting of convective events (Chan 2009; Madhulatha et al. 2013), boundary layer studies (Güldner and Spänkuch 2001) and Knupp et al. (2009) showed the capabilities of MWR in operational forecasting during dynamic weather conditions. In addition, with the advantage of monitoring stability and turbulence, the MWRs have been used together with lidar to measure wind and temperature for wind energy applications (Friedrich et al. 2012). Rambabu et al. (2014) studied forward model-based brightness temperature variations over different regions in India using radiosonde and MWR measurements. Güldner and Spänkuch (1999) showed increases in the parameter such as the liquid water content and precipitable water (PW) vapour $2 \mathrm{~h}$ before the rain. The use of a collocated windprofiler and MWR observations for monsoon studies (Balaji et al. 2017) was made over the Indian subcontinent.

The Indian subcontinent has two principal monsoon seasons which enriches the country's agriculture production. The south-west monsoon season (June-September) contributes about 70-90\% of rainfall (Pant and Rupa Kumar 1997) in most parts whereas the NEM season (October-December) contributes $50 \%$ of annual rainfall in the south-eastern tip of the Indian peninsula (Kumar et al. 2007) which constitutes coastal Andhra Pradesh, Rayalaseema, south interior Karnataka, Kerala and Tamil Nadu (TN). The onset of low-level easterlies precedes and serves as a precursor to the onset of NEM rains over coastal TN (CTN) after mid-October. Several studies on NEM performance such as spatial and temporal rainfall variability, its onset, withdrawal, etc. have been studied by Rao Krishna and Jagannathan (1953), Dhar and Rakhecha (1983), Raj and Jamadar (1990), Raj (1998) and Rajeevan et al. (2012). NEM rainfall variability with coupled ocean-atmosphere phenomena like El Nino/southern oscillation and the Indian Ocean dipole have studied widely in the present century with different statistical approaches (Raj 1989; Balachandran et al. 2006; Kumar et al. 2007). Prediction of NEM has also been attempted by some of the authors like Rajeevan et al. (2012), using coupled climate models. The criteria followed by IMD for declaring NEM onset are withdrawal of the south-west monsoon up to $15^{\circ} \mathrm{N}$, persistent of surface easterlies over the Tamil Nadu coast up to a depth of $850 \mathrm{hPa}$ along with fairly widespread rainfall over coastal Tamil Nadu and the adjoining areas. Onset is not to be declared before 10th
October even, if the conditions described above exist. The rainfall during this season is due to the synoptic/sub-synoptic systems like tropical cyclones, depressions, easterly waves, north-south trough activity and coastal convergence.

For convective activity estimation, thermodynamic indices like CAPE, $K$ index (KI), total totals index (TTI), etc. which measures the stability of the atmosphere is very useful. Numerous studies have reported the importance of indices in predicting the severe weather (Galway 1956; Schultz 1989). Studies have reported convective activity with various parameters like PW, clouds, outgoing long wave radiation, etc. Based on the topography and environmental conditions of a particular station, the thresholds of these indices may vary. Recent studies on Indian weather conditions have been using these indices to issue short range forecast of thunderstorms and hailstorms (Suresh and Bhatnagar 2004; Mukhopadhyay et al. 2003). In this paper, an attempt has been made to predict NEM onset features using thermodynamic indices along with other atmospheric parameters.

SHAR receives abundant rainfall $(60 \%)$ in the NEM season $(800 \mathrm{~mm})$ than in the south-west monsoon of total annual rainfall. During the time of onset, major amount of rainfall is received for interior Tamil Nadu and SHAR associated with systems like low pressure systems and easterly wave activity. With this importance, the present study is carried out to investigate precursory parameters for NEM onset features using MWR observations. Continuous vertical profiles of temperature and humidity show significant promise for understanding the moisture transport, clouds and precipitation embedded within the monsoon convection.

\subsection{Microwave radiometer}

Ground-based MWR provides accurate and continuous vertical profiles of temperature and water vapour up to $10 \mathrm{~km}$ in both clear and cloudy conditions. MWR used in this study is developed and maintained by radiometrics (MP-3166A). Atmospheric temperature and humidity profiles will be computed from atmospheric brightness temperature measurements at selected frequencies (35 channels) in the water vapour absorption band $(22-30 \mathrm{GHz})$ and oxygen absorption band $(51-60 \mathrm{GHz})$. These profiles are derived from measured brightness temperatures with a neural network based retrieval algorithm (Solheim et al. 
1998). It provides the profiles at a vertical resolution of $50 \mathrm{~m}$ from 0 to $500 \mathrm{~m}, 100 \mathrm{~m}$ from $500 \mathrm{~m}$ to $2 \mathrm{~km}$ and $250 \mathrm{~m}$ from 2 to $10 \mathrm{~km}$. Additionally, the instrument is equipped with surface sensors.

\section{Data and methodology}

MWR installed over SHAR in 2014 is in round the clock operation for providing day-to-day thermodynamic variability in the atmosphere. High resolution Pisharoty radiosondes developed by the Indian Space Research Organisation (ISRO) were used for the initial validation of the system for this region. This validation has done for different seasons individually. For validation, total 54 ascents from 2014 to 2016 available ascents in NEM were considered which are released at 09:00 UTC from SHAR and the sample analysis during the NE monsoon is presented in figure 1. The mean and standard deviation of temperature and vapour density for the NEM season were well comparable with radiosonde (figure $1 \mathrm{a}$ and $\mathrm{b}$ ). Difference between radiosonde and MWR is shown in figure 1(c). Comparison is good at the lower levels (below $1.5 \mathrm{~km}$ ) after that the deviation is more due to the drift associated with the balloon during the NEM season (more than $8 \mathrm{~km}$ away from the release position). MWR shows a warm bias with respect to radiosonde. The correlation coefficient is 0.99 for temperature and 0.96 for vapour density at the surface level. The biases and standard deviations at each vertical level were estimated for clear and cloudy conditions.

Observed biases can be attributed to the measurement technique of two instruments and also due to the significant drift of the radiosonde from the base station due to strong winds associated with the monsoon (Madhulatha et al. 2013). In the present study, we try to investigate preNEM and during NEM onset features over SHAR using MWR-based temperature and moisture proles for the years 2014, 2016 and 2017 (2015 is an El Nin̈o year). With the capability of high temporal resolution measurements of temperature and water vapour, MWR provides continuous monitoring of the thermodynamic state of the atmosphere like CAPE, KI, etc. which will be used to investigate the pre-monsoon and monsoon environments over the region. A study carried out over SHAR for
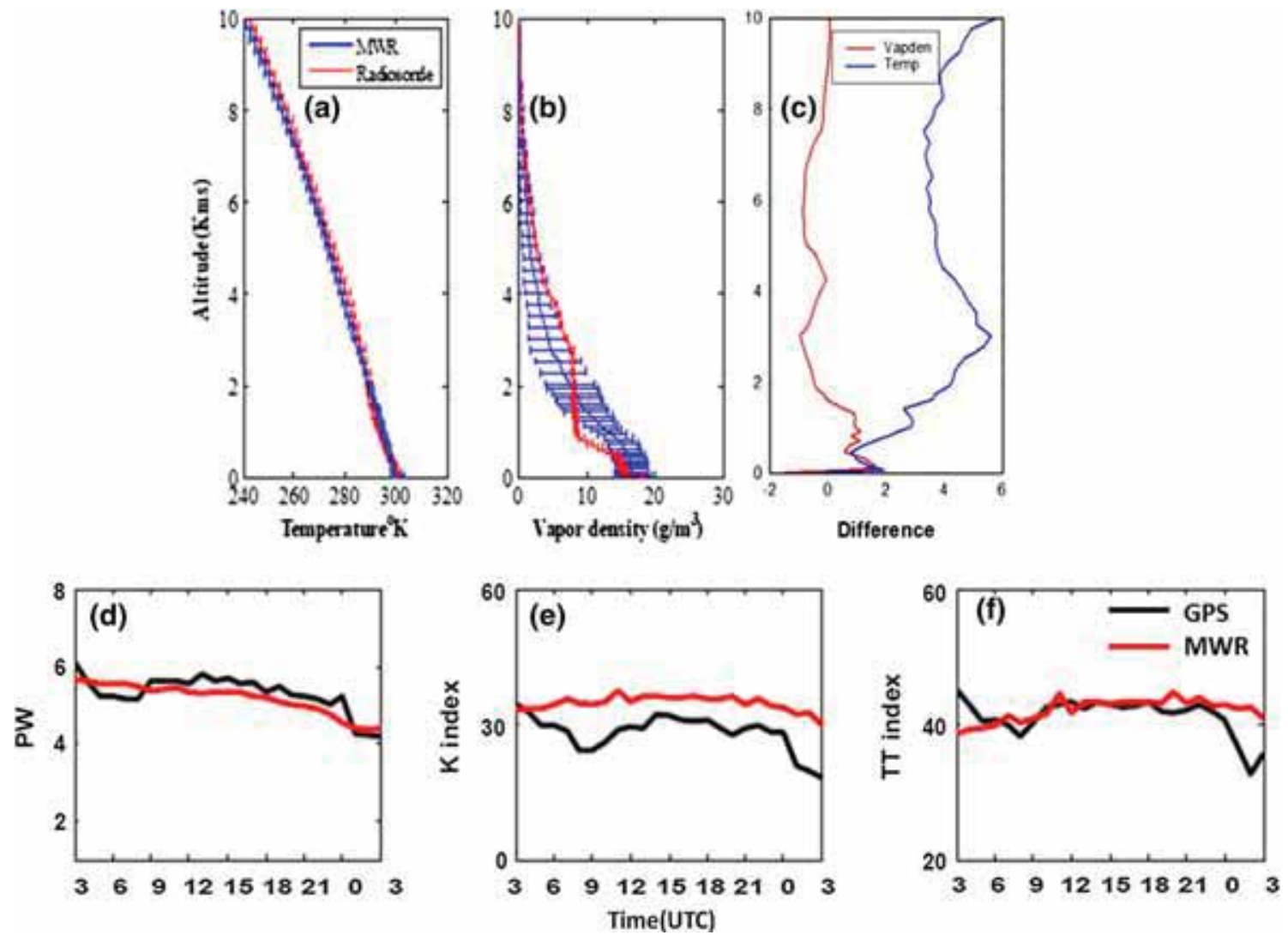

Figure 1. Comparison of (a) temperature and (b) vapour density profiles with standard deviation and mean (c) difference, (d) PW, (e) KI and (f) TTI for the NEM season. 
thunderstorm cases using thermodynamic indices have resulted in good precursors with these six indices after considering all available indices (Pushpa Saroja et al. 2016). Hence for this study these indices were considered. For comparison of indices from MWR and radiosonde, special hourly diurnal campaign observations starting from 03:00 UTC to next day 03:00 UTC were used. The indices comparison for the NEM season (28 and 29 October 2014) are shown in figure 1(d) for PW, KI (figure 1e) and TTI (figure 1f). These features are analysed along with the European Centre for Medium-Range Weather Forecasts (ECMWF) and the operational WRF model forecast and observations from IMD.

One week before onset were considered based on the MWR rain flag and collocated conventional rain gauge. The variations of thermodynamic parameters associated with the NEM onset are examined and illustrated over Sriharikota. For identifying and analysing the synoptic features, we used NWP products of ECMWF and operational WRF model during the onset phase. ECMWF reanalysis data were considered for the study for 1 week prior to onset for each year considered with $0.75^{\circ} \times 0.75^{\circ}$ resolution.

(a)

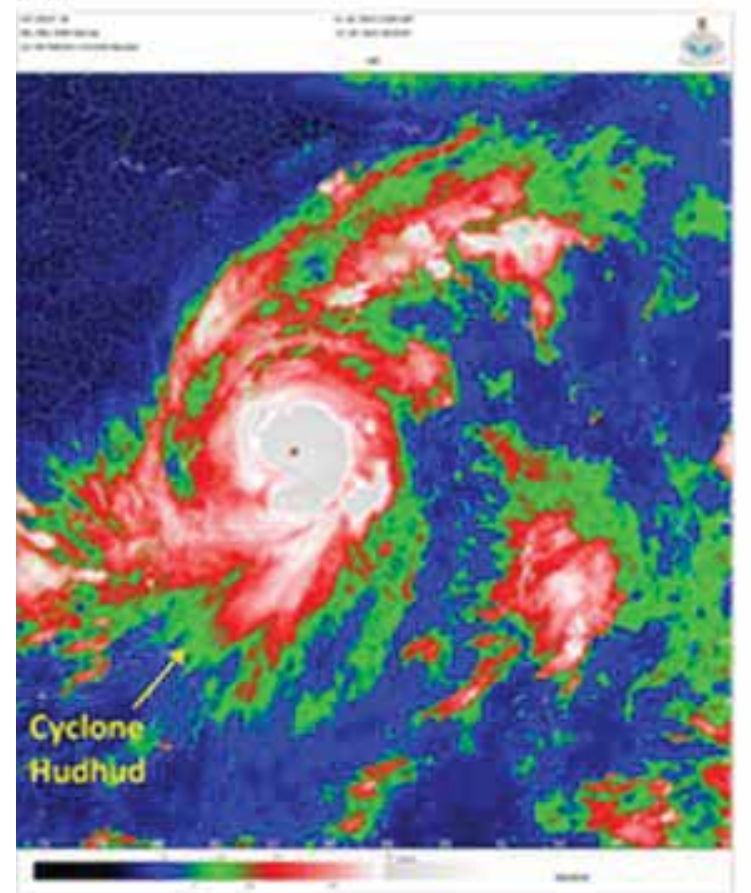

\section{Results and discussions}

MWR is used in the present study for analysing pre-NEM onset features for the non-El Nin̈o years 2014, 2016 and 2017 (2015 is an El Nin̈o year). One week prior to onset vapour density, liquid water and relative humidity along with thermodynamic indices are considered. Six thermodynamic indices, total PW, TTI, convective temperature (CvT), KI, delta equivalent potential temperature $(\Delta \theta \mathrm{e})$ and lifting condensation level (LCL), are used for the study.

\subsection{Synoptic features of NEM onset during the year 2014}

In October 2014, a very severe cyclonic storm HUDHUD developed over the Bay of Bengal and crossed over Visakhapatnam on 12 October 2014 (figure 2a) with strong gale winds. It triggered 2 days early onset of NEM over south-east peninsular India. NEM onset is on 18 October 2014. The establishment of north-easterly winds over south peninsular India from Chennai direct web remoting (DWR) for the year 2014 is shown in figure 2(b). (b)

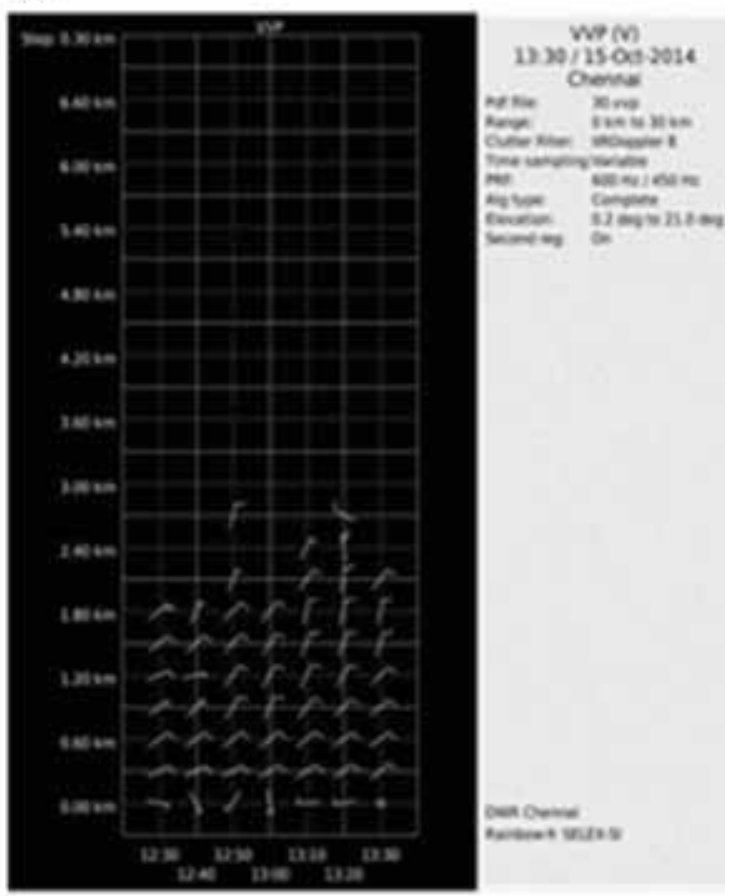

Figure 2. ( $\mathbf{a}$ and $\mathbf{b})$ Satellite images of the severe cyclonic storm HUDHUD and horizontal wind from Chennai DWR as the north-easterly winds approaching. 


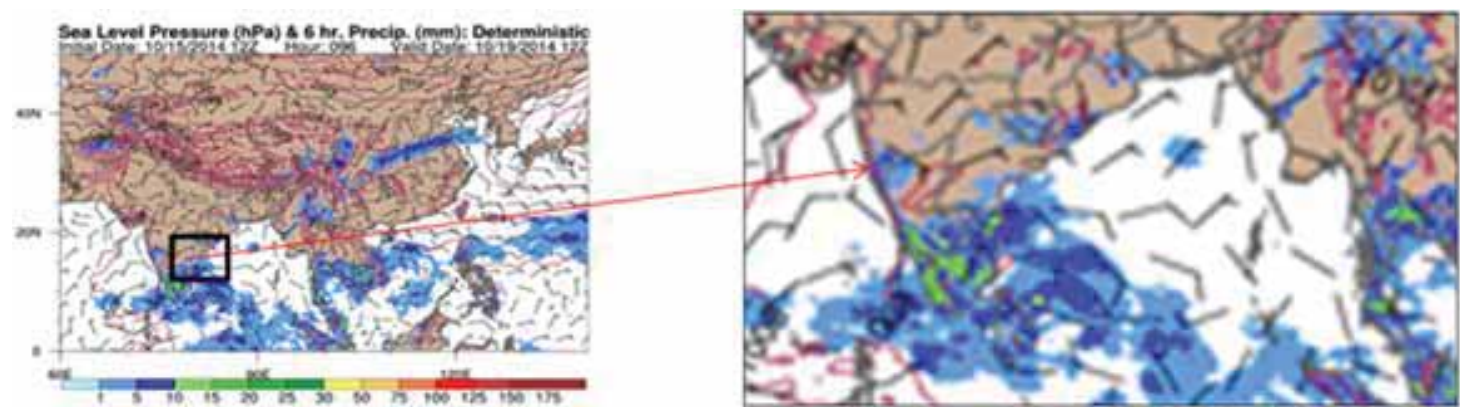

Figure 3. ECMWF model-derived sea-level pressure, based on 15 October 12 UTC initial conditions for 19 October 2014.

(a)

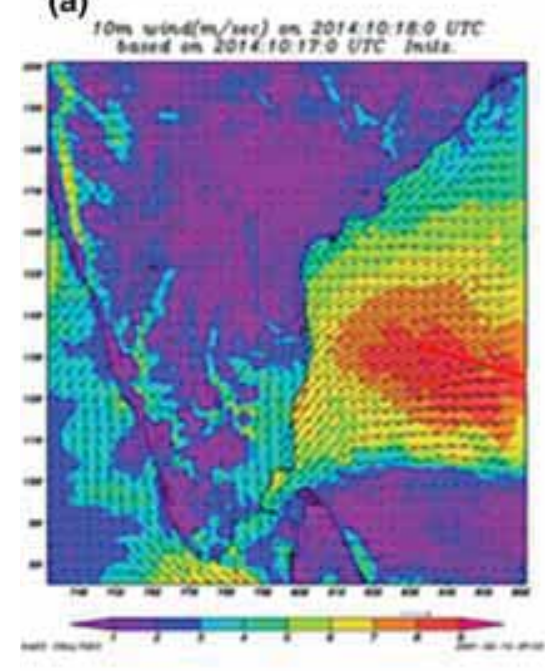

(b)

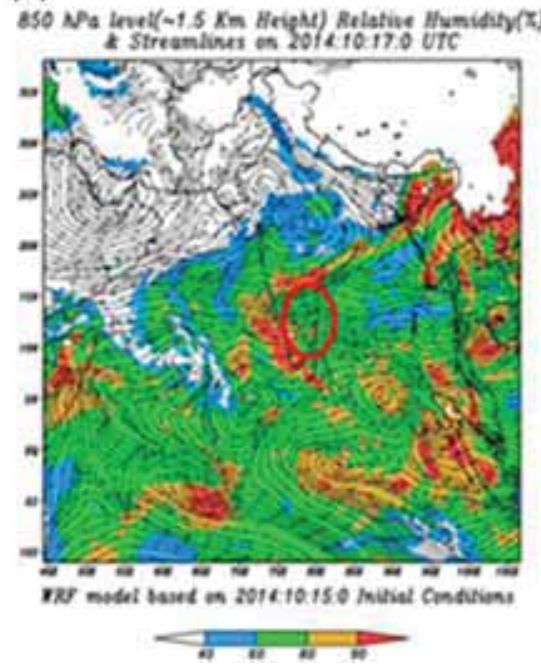

(c)

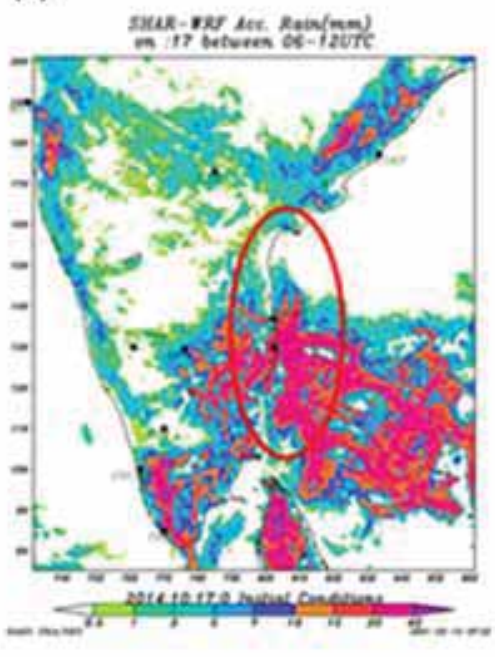

Figure 4. Operational WRF model derived products of (a) 10-m wind, (b) wind streamlines at 850 hPa and relative humidity and (c) accumulated rainfall for the year 2014 prior to onset.

Mean sea level pressure, 6 -h precipitation (figure 3) in the extreme south peninsular India represents precipitation over the region with north-easterly winds from the deterministic ECMWF model (Miller et al. 2010). Operational WRF model $3.4 \mathrm{~V}$ with two-way nested domains configuration of 27 and $9 \mathrm{~km}$. Model physics used in the study for boundary layer processes at Yonsei University, the Kain-Fritsch for cumulus convection, Thompson graupel scheme for microphysics and rapid radiations transfer model for long wave radiation are used. WRF model derived 10-m wind (figure 4a) indicates an increase in wind speed over south peninsular India on onset day, wind streamlines at $850 \mathrm{hPa}$ and relative humidity (figure $4 \mathrm{~b}$ ), and accumulated rainfall (figure 4c) over the east coast of India due to the arrival of NE winds on 17 October 2014 based on the initial conditions on 17th October.

\subsubsection{MWR observations during 2014 NEM onset}

One week prior to onset warm temperatures were observed in the lower troposphere, later temperatures reduced by $5^{\circ} \mathrm{C}$ and moisture increased in the lower $\left(25 \mathrm{~g} / \mathrm{m}^{3}\right)$ and mid-troposphere as seen in the time height cross-section plots of (a) vapour density $\left(25 \mathrm{~g} / \mathrm{m}^{3}\right)$, (b) liquid water $\left(2 \mathrm{~g} / \mathrm{m}^{3}\right)$ and (c) relative humidity (90\%) for the year 2014 as shown in figure 5 . The pink bars in the cross-section plot of relative humidity (figure 5c) represent that amount of rainfall on that particular day in $\mathrm{mm}$. Further thermodynamic indices are also analysed prior to onset. Meanwhile, during dry conditions, rather low shear and lower PW support reduction in cloud formation and the surface sensible heat flux may enhance driving stronger thermals and more 

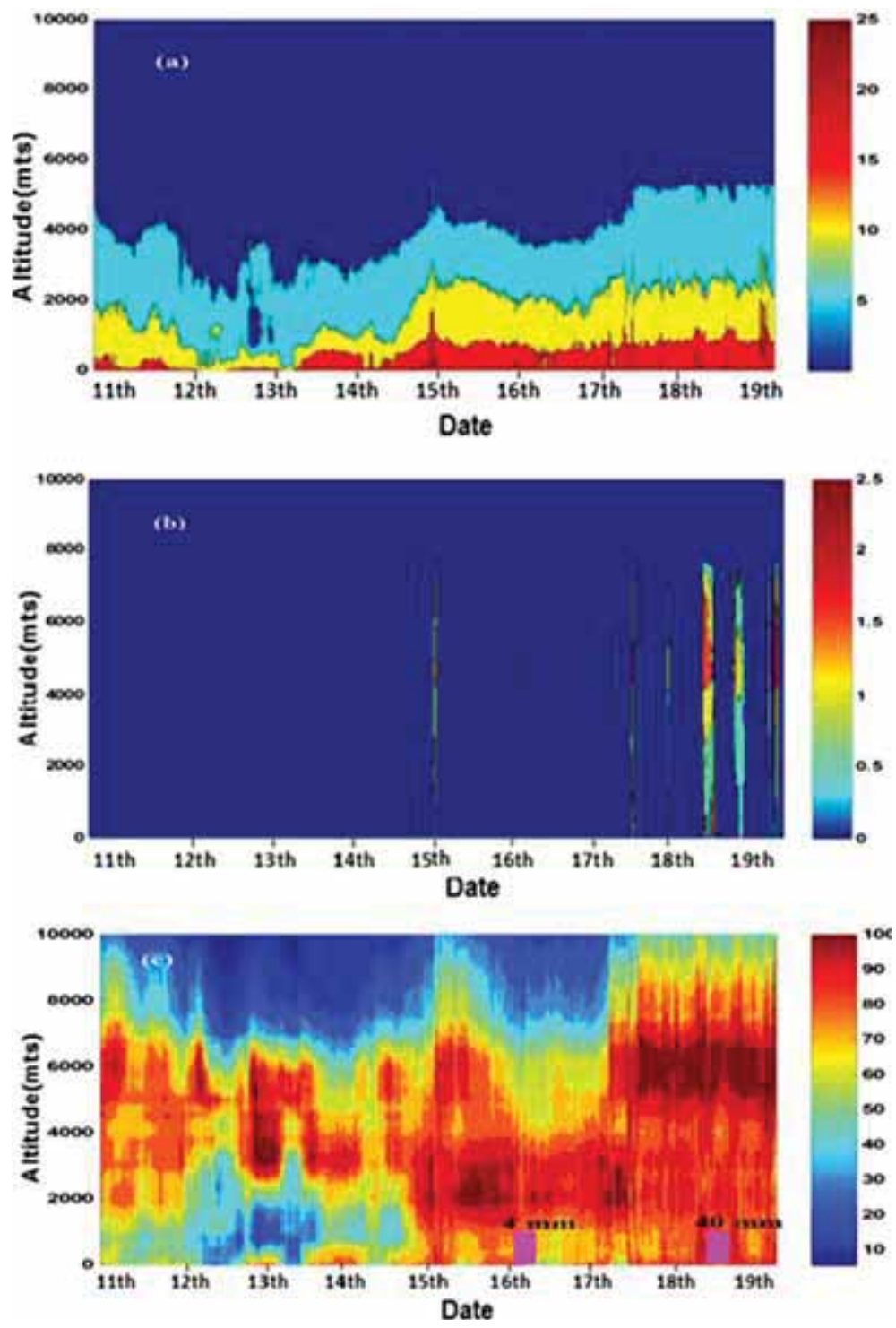

Figure 5. Time height cross section of (a) vapour density $\left(\mathrm{g} / \mathrm{m}^{3}\right),(\mathbf{b})$ liquid water $\left(\mathrm{g} / \mathrm{m}^{3}\right)$ and $(\mathbf{c})$ relative humidity $(\%) 1$ week before the NEM onset 2014. Pink bars represent the rainfall amount observed on the particular day. The $x$-axis represents the dates of October 2014. Red line indicates date of NEM onset.

vigorous boundary layer convection (Balaji et al. 2017). This indeed also led to the growth of LCL. Buoyant thermals reach greater heights in the dry boundary layer. PW and LCL height relationships have been discussed by Murugavel et al. (2016).

In this year, from 14th October, a gradual increase in PW $(\mathrm{cm})$, KI $\left({ }^{\circ} \mathrm{C}\right)$ and TTI $\left({ }^{\circ} \mathrm{C}\right)$ values and a simultaneous decrease in delta equivalent potential temperature $\Delta \theta \mathrm{e}\left({ }^{\circ} \mathrm{C}\right), \mathrm{CvT}\left({ }^{\circ} \mathrm{C}\right)$ and LCL $(\mathrm{m})$ values are observed (figure 6 ). The red line indicates the date of NEM onset.

Daily rainfall and relative humidity from 12 to 19 October 2014 over SHAR are shown in figure 7(a). Rainfall occurred on 15th October with an increase in relative humidity.
Results from the ECMWF reanalysis for the year 2014 were shown in figure 8 . For south peninsular India, 1 week prior to onset $\mathrm{PW}$ is in lesser amounts $\left(<4 \mathrm{~g} / \mathrm{cm}^{2}\right)$ at the southern tip of India, i.e., on 12 October 2014 (figure 8a). After the onset on 19 October 2014 (figure 8b), the PW in the same area has increased resulting in an increase $\left(>5.5 \mathrm{~g} / \mathrm{cm}^{2}\right)$ of moisture due to the arrival of the north-easterlies. Time series of PW variation from 12th to 18th October were plotted for Chennai and Bangalore (prone to NEM). A drastic increase of PW over Chennai is seen (figure 8c) from 3.4 to $4.8 \mathrm{~g} / \mathrm{cm}^{2}$. A slight increase in $\mathrm{PW}$ is seen in Bangalore (figure 8d) from 3.5 to $4.1 \mathrm{~g} / \mathrm{cm}^{2}$. This is due to the north-easterlies arriving first at Chennai, and then later slowly shifting towards the north. 

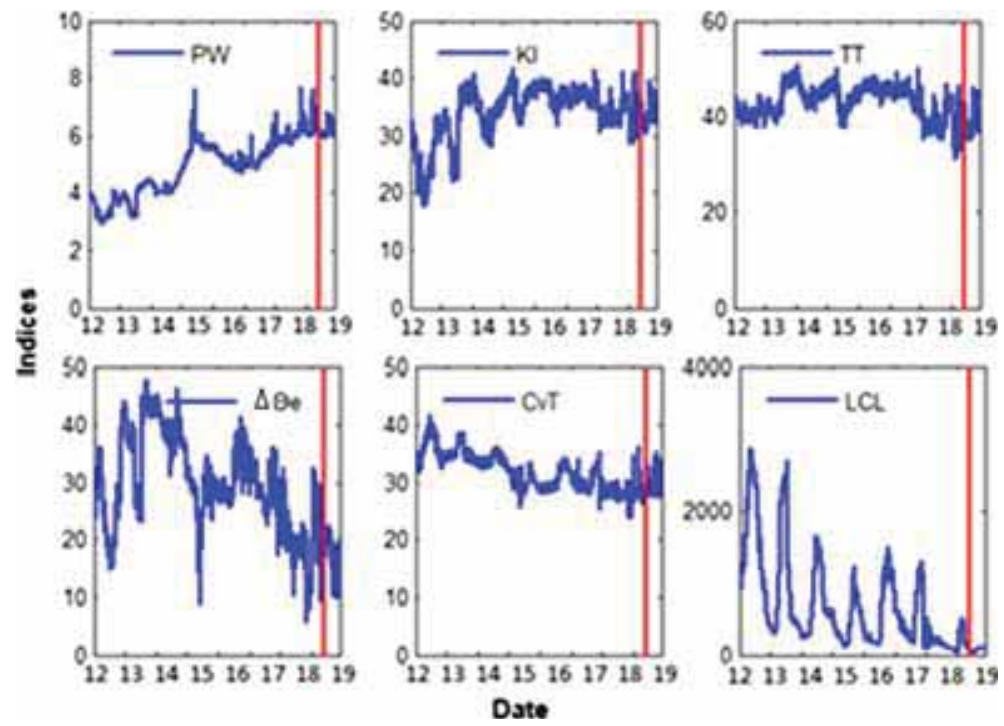

Figure 6. Thermodynamic indices variation before NEM onset, for the year 2014. Red line indicates date of onset. The $x$-axis represents the dates of October month prior to onset.
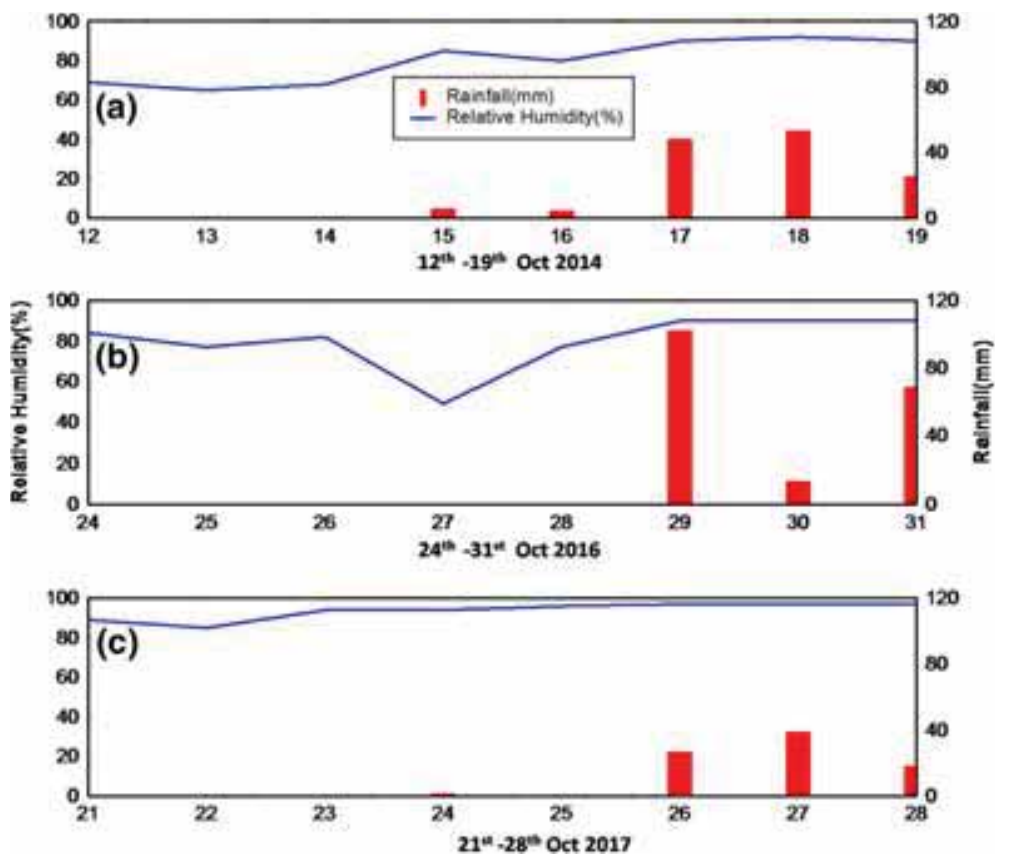

Figure 7. Daily rainfall and relative humidity over SHAR for the years: (a) 2014, (b) 2016 and (c) 2017,1 week prior to the NEM onset.

\subsection{Synoptic features of NEM onset during the year 2016}

In 2016, the SW monsoon has extended up to the second half of October month and the formation of the cyclonic storm KYANT (figure 9a) in the Bay of Bengal led to a late onset of $\mathrm{NE}$ monsoon by 10 days of normal onset i.e., on 30 October 2016. NEM onset is on 30 October 2016. The establishment of north-easterly winds from the horizontal wind from Chennai DWR for the year 2016 is shown in figure $9(\mathrm{~b})$ and $850 \mathrm{hPa}$ streamlines and mean sea level pressure and $24 \mathrm{~h}$ precipitation from the deterministic ECMWF model (figure 10a and $\mathrm{b}$ ). The operational WRF model derived $10 \mathrm{~m}$ wind (figure 11a) around a low pressure system, wind streamlines at $850 \mathrm{hPa}$ and relative humidity (figure 11b) with moisture intrusion from the Bay of Bengal, and accumulated rainfall (figure 11c) along the east coast of India on 30 October 2016 based on 29 October initial conditions. 

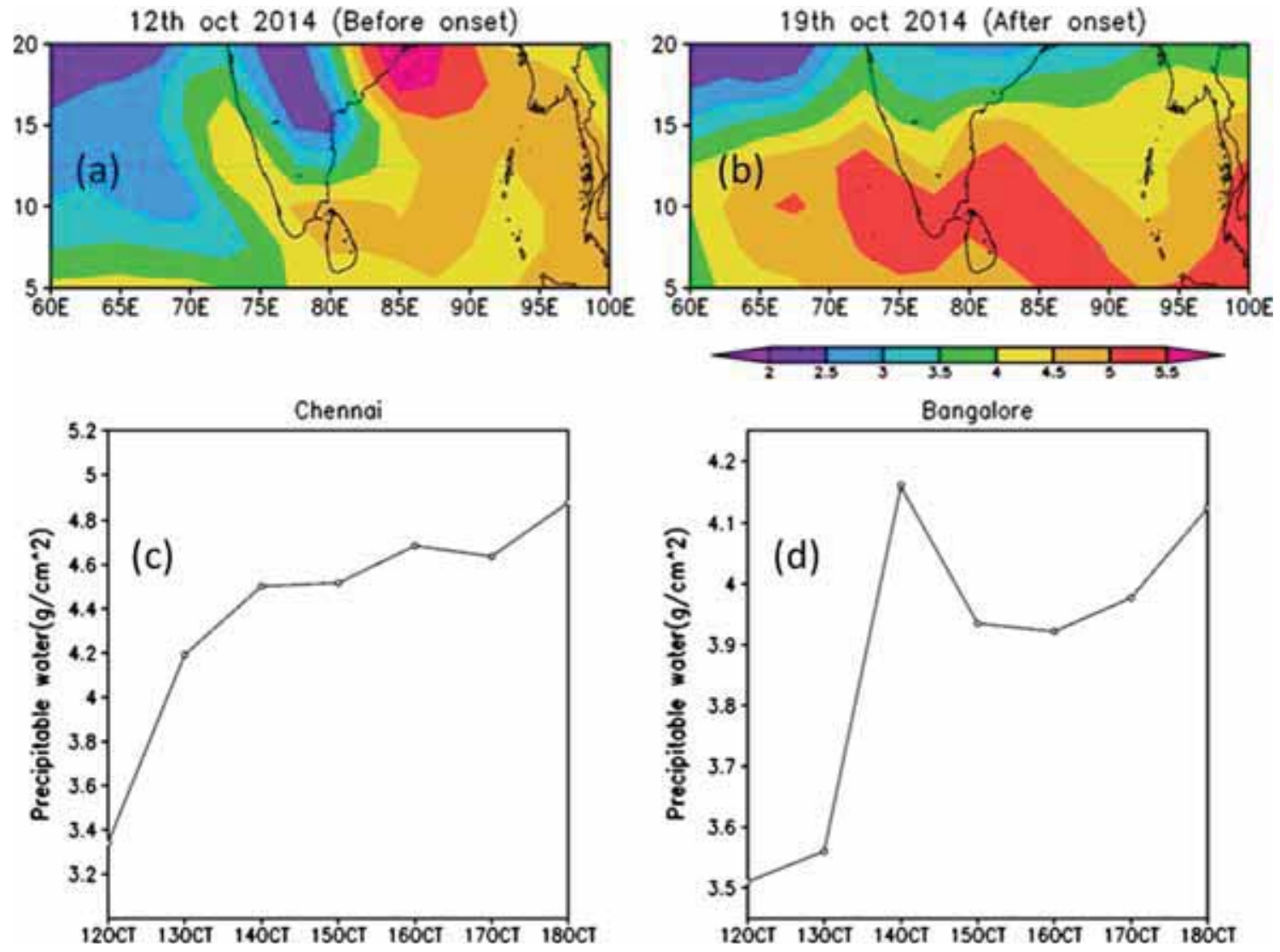

Figure 8. PW from ECMWF reanalysis for 1 week prior to onset for the year 2014: (a) before onset, (b) after onset, (c) daily PW from 12 th to 18 th October for Chennai and (d) same as (c) but for Bangalore.

(a)

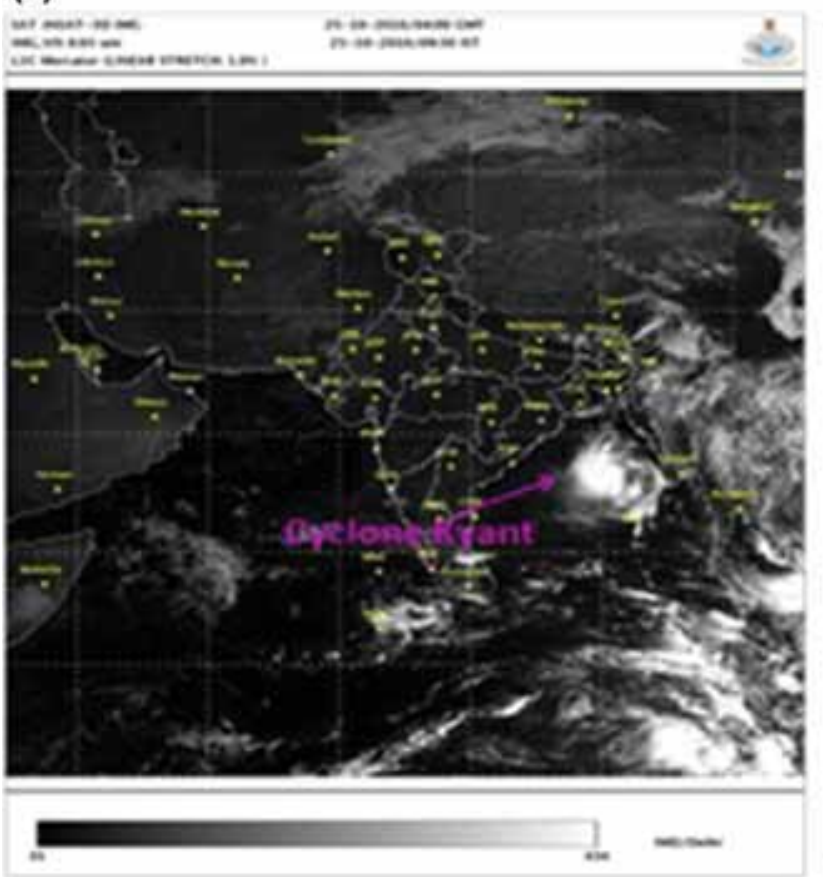

(b)

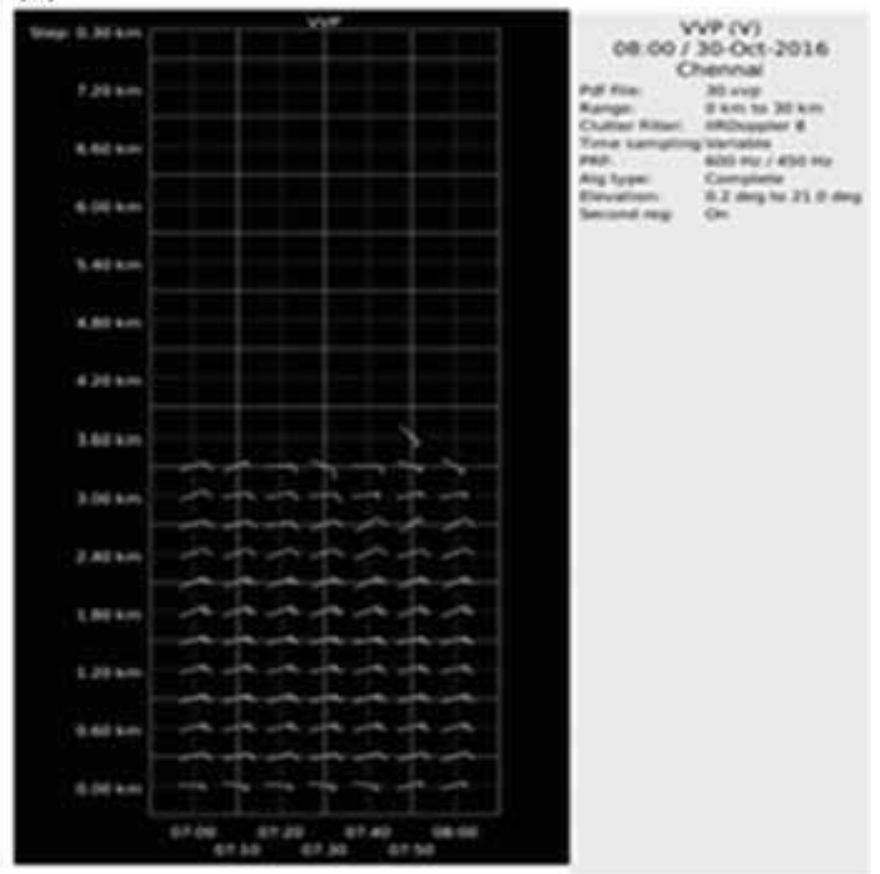

Figure 9. (a) Satellite image of cyclonic storm KYANT in 2016 and (b) horizontal wind from Chennai DWR as the northeasterly winds approaching. 
(a)

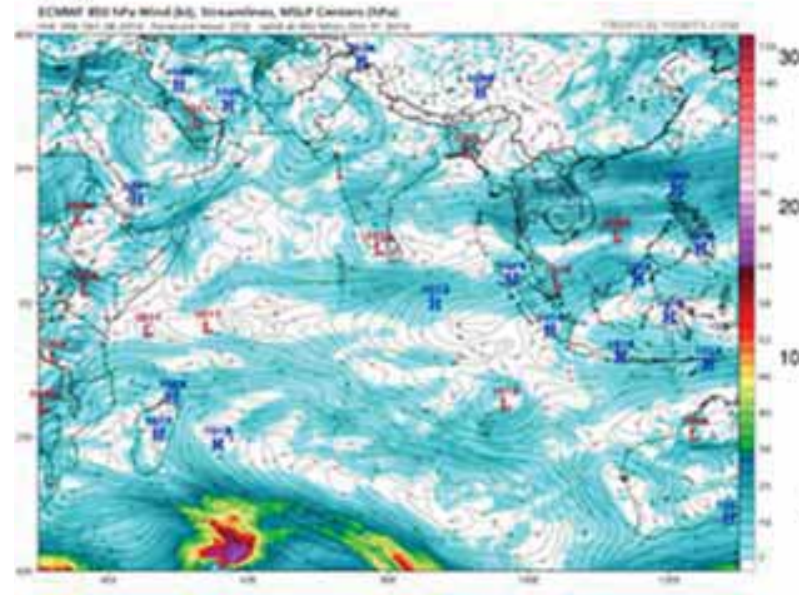

(b)

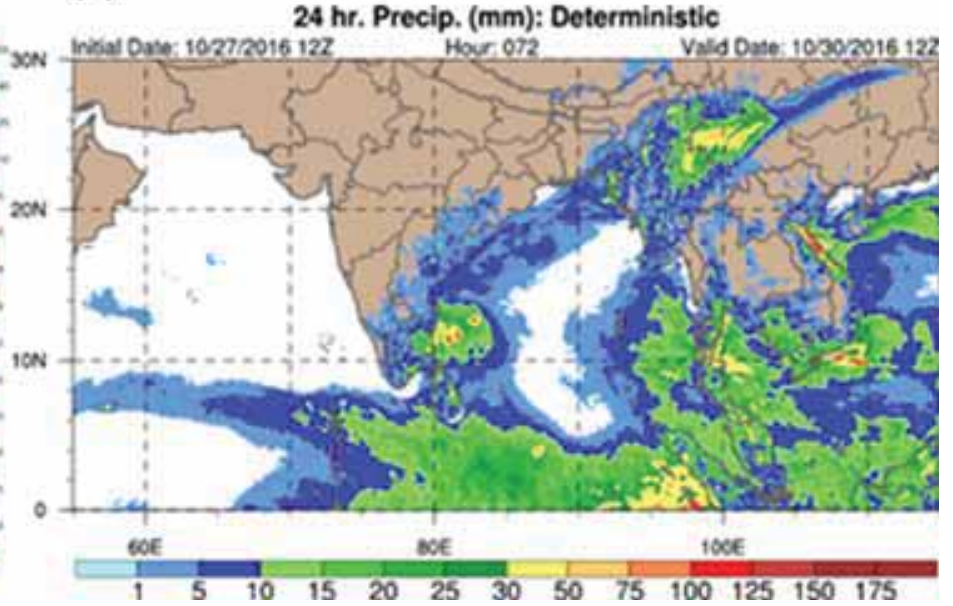

Figure 10. (a) ECMWF model derived sea level pressure, winds and (b) deterministic precipitation based on 28th October 00 UTC initial conditions for 30 October 2016.

(a)

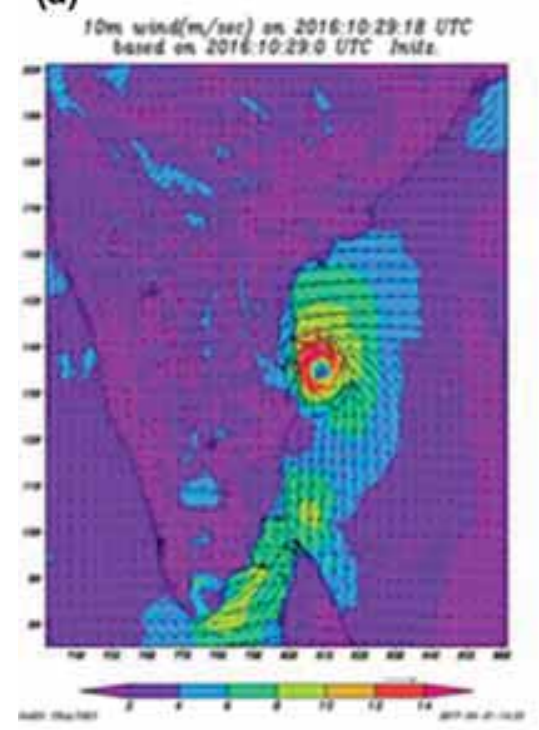

(b)

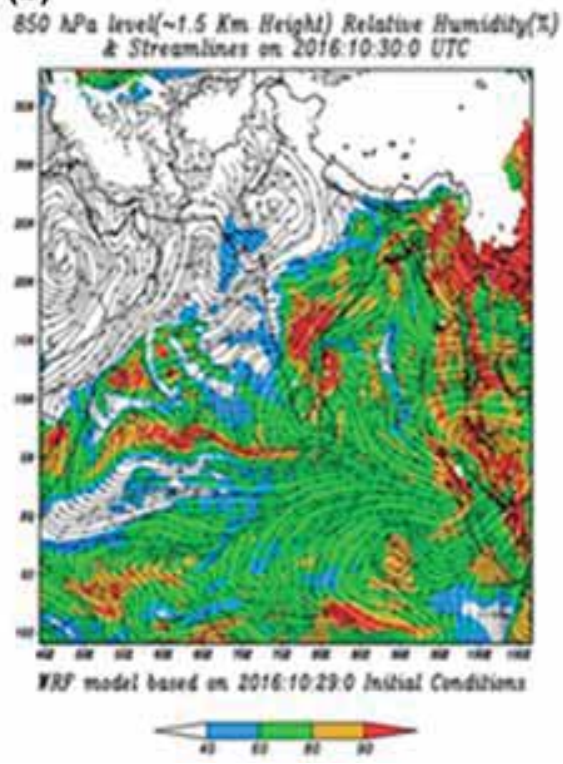

(c)

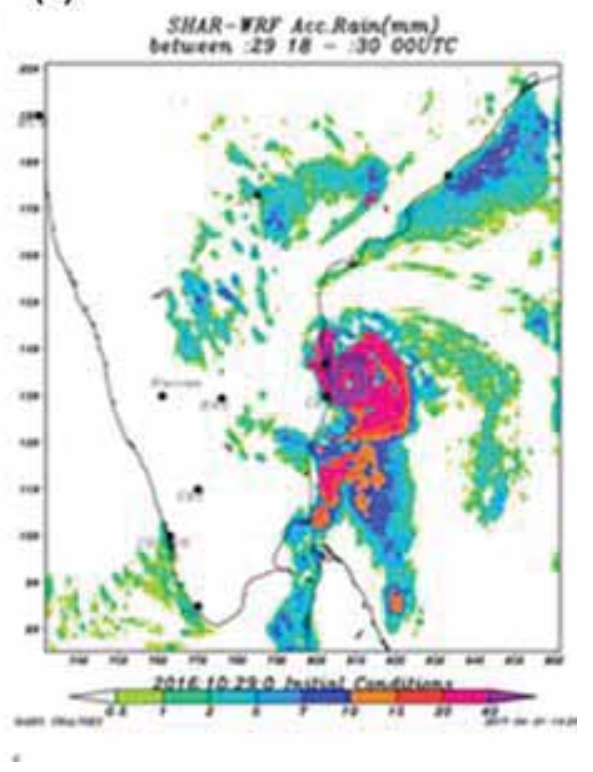

Figure 11. Operational WRF model derived products of (a) 10-m wind, (b) wind streamlines at 850 hPa and relative humidity and (c) accumulated rainfall for the year 2016 prior to onset.

\subsubsection{MWR observations during 2016 NEM onset}

In 2016, cyclone KYANT over the east-central Bay of Bengal moved further west-south-westwards. However, with its recurving features towards the west-south-westward close to the south-east coast of India, a gradual increase in mid tropospheric moisture is observed from 28 October 2016. i.e., 2 days before the date of onset (figure 12) (NEM onset is on 30 October 2016). A sharp increase in (a) vapour density $\left(23 \mathrm{~g} / \mathrm{m}^{3}\right)$, (b) liquid water $\left(1.8 \mathrm{~g} / \mathrm{m}^{3}\right)$ and (c) relative humidity $(90 \%)$ are clearly visible prior to the onset. It is interesting to note that vapour density and relative humidity increased sharply at the lower troposphere (almost 3 days in advance) later complete saturation in the entire column is shown in figure 12(c). Due to lower PW support resulting in lesser total cloud amount leads to high temperatures before NE monsoon onset. In this year, from 27 October, a gradual increase in PW, KI and TTI values and simultaneous decrease in delta equivalent potential temperature $\Delta \theta \mathrm{e}, \mathrm{CvT}$ and LCL values are observed in figure 13.

Daily rainfall and relative humidity prior to 1 week before onset for the year 2016 over SHAR are shown in figure $7(\mathrm{~b})$. Rainfall occurred on 29 October with the increase of relative humidity. 

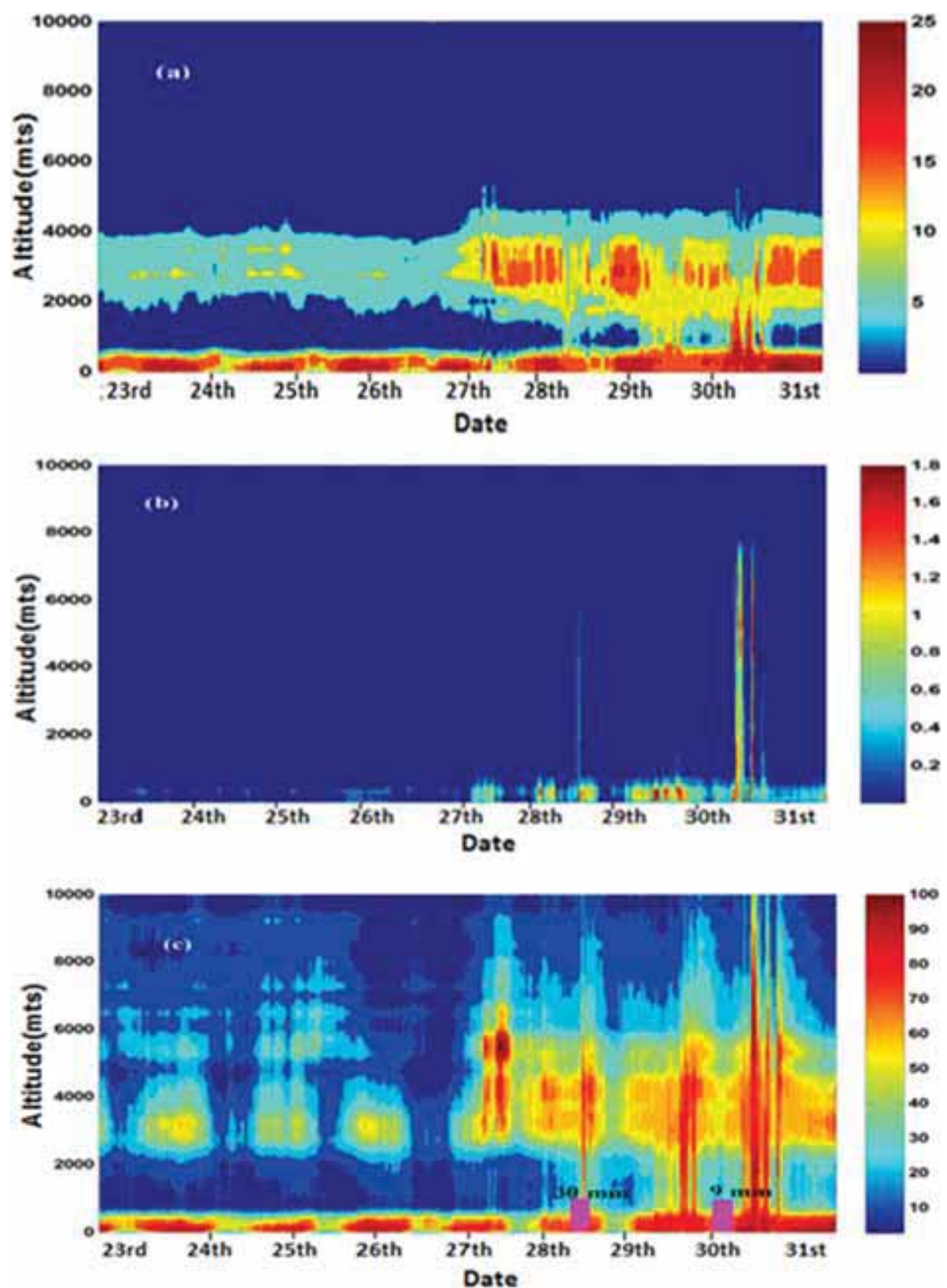

Figure 12. Time height cross section of (a) vapour density $\left(\mathrm{g} / \mathrm{m}^{3}\right),(\mathbf{b})$ liquid water $\left(\mathrm{g} / \mathrm{m}^{3}\right)$ and $(\mathbf{c})$ relative humidity $(\%)$ for the year 2016 before onset. Pink bars represent the rainfall amount observed on the particular day. The $x$-axis represents the dates of October 2016. The red line indicates the date of NEM onset.

Results from ECMWF reanalysis for the year 2016 are shown in figure 14. For the south peninsular India, 1 week prior to onset $\mathrm{PW}$ is in lesser amounts $\left(<3 \mathrm{~g} / \mathrm{cm}^{2}\right)$ at the southern tip of India i.e., on 24 October 2016 (a). After the onset on 31 October 2016 (b) the PW in the same area has increased $\left(>5 \mathrm{~g} / \mathrm{cm}^{2}\right)$, resulting in an increase of moisture due to the arrival of the north-easterlies. Time series of PW variation from 24th to 30th October were plotted for Chennai and Bangalore (prone to NEM). A drastic increase of $\mathrm{PW}$ over Chennai is seen (c) from 2.4 to $4.5 \mathrm{~g} / \mathrm{cm}^{2}$. A slight increase in $\mathrm{PW}$ is seen in Bangalore (d) from 2.5 to $4 \mathrm{~g} / \mathrm{cm}^{2}$.

Wind speed and direction from GPS radiosonde are plotted for the year 2016 to show wind variations from the south-west winds to the arrival of the north-east winds over SHAR with the available data sets. North-easterly winds are observed after onset on 31 October 2016 as shown in figure 15. 

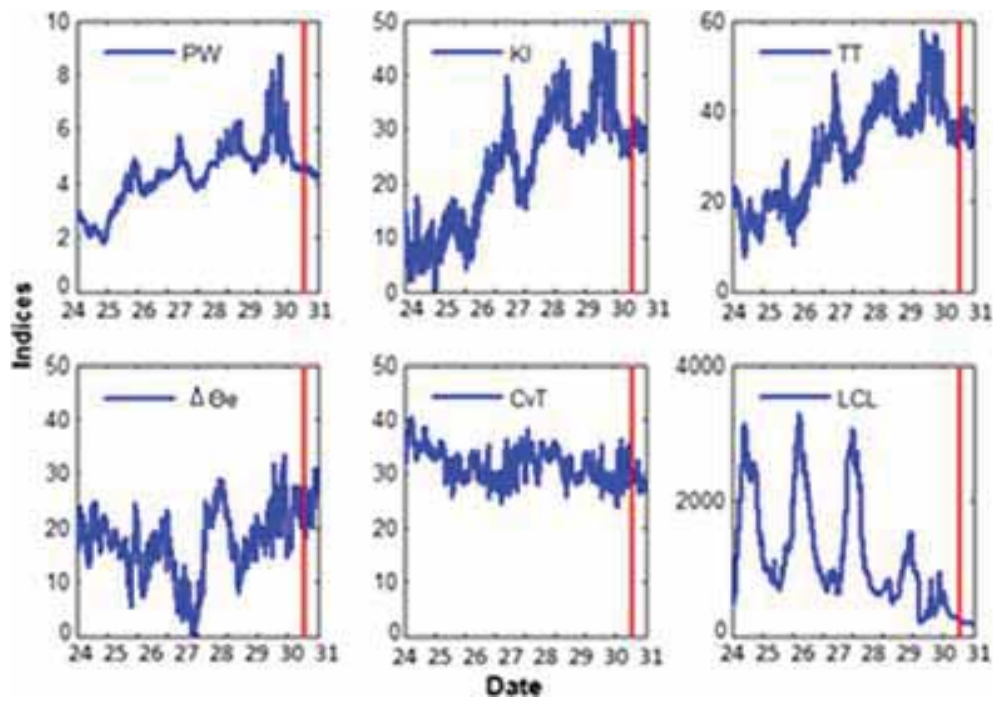

Figure 13. Thermodynamic indices variation before NEM onset, for the year 2016. The red line indicates date of onset. The $x$ axis represents the dates of October prior to onset.
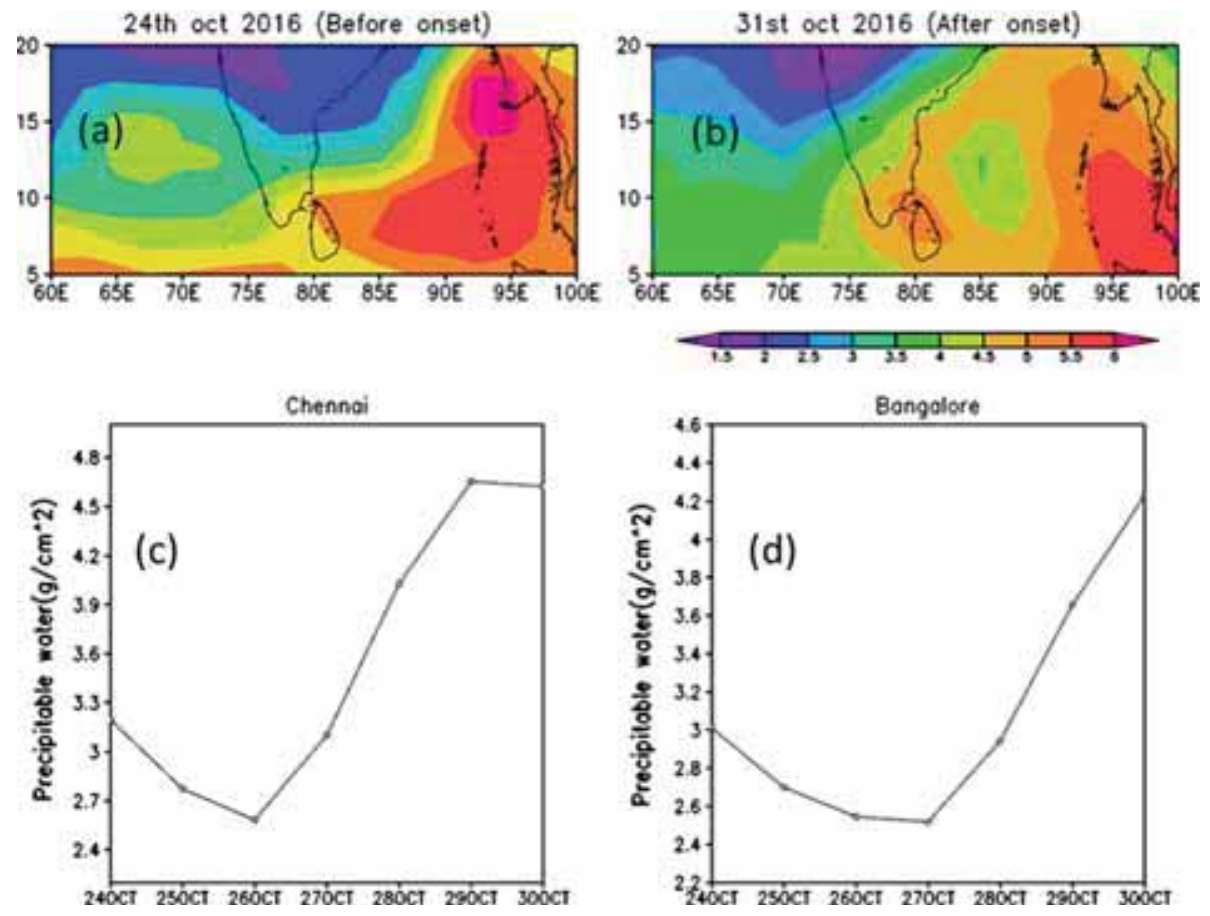

Figure 14. PW from ECMWF reanalysis for 1 week prior to onset for the year 2016 (a) before onset, (b) after onset, (c) daily PW from 24th to 30th October for Chennai and (d) same as (c) but for Bangalore.

\subsection{Synoptic features of NEM onset during the year 2017}

In 2017, the establishment of north-easterly winds in the lower tropospheric levels along the east coast and the NEM rains commenced over Tamil Nadu and Puducherry, Kerala and adjoining areas of Andhra Pradesh and Karnataka on 27 October 2017 with the formation of low pressure in the Bay of Bengal with the corresponding satellite image in figure 16(a) and horizontal wind based on cloud motions from Chennai DWR (figure 16b). NEM onset is on 27 October $201724 \mathrm{~h}$ deterministic precipitation and $850 \mathrm{hPa}$ relative vorticity from the ECMWF model (figure 17a and b). Forecast shows rainfall over the east coast of India and a dry period for the northern parts of India. 

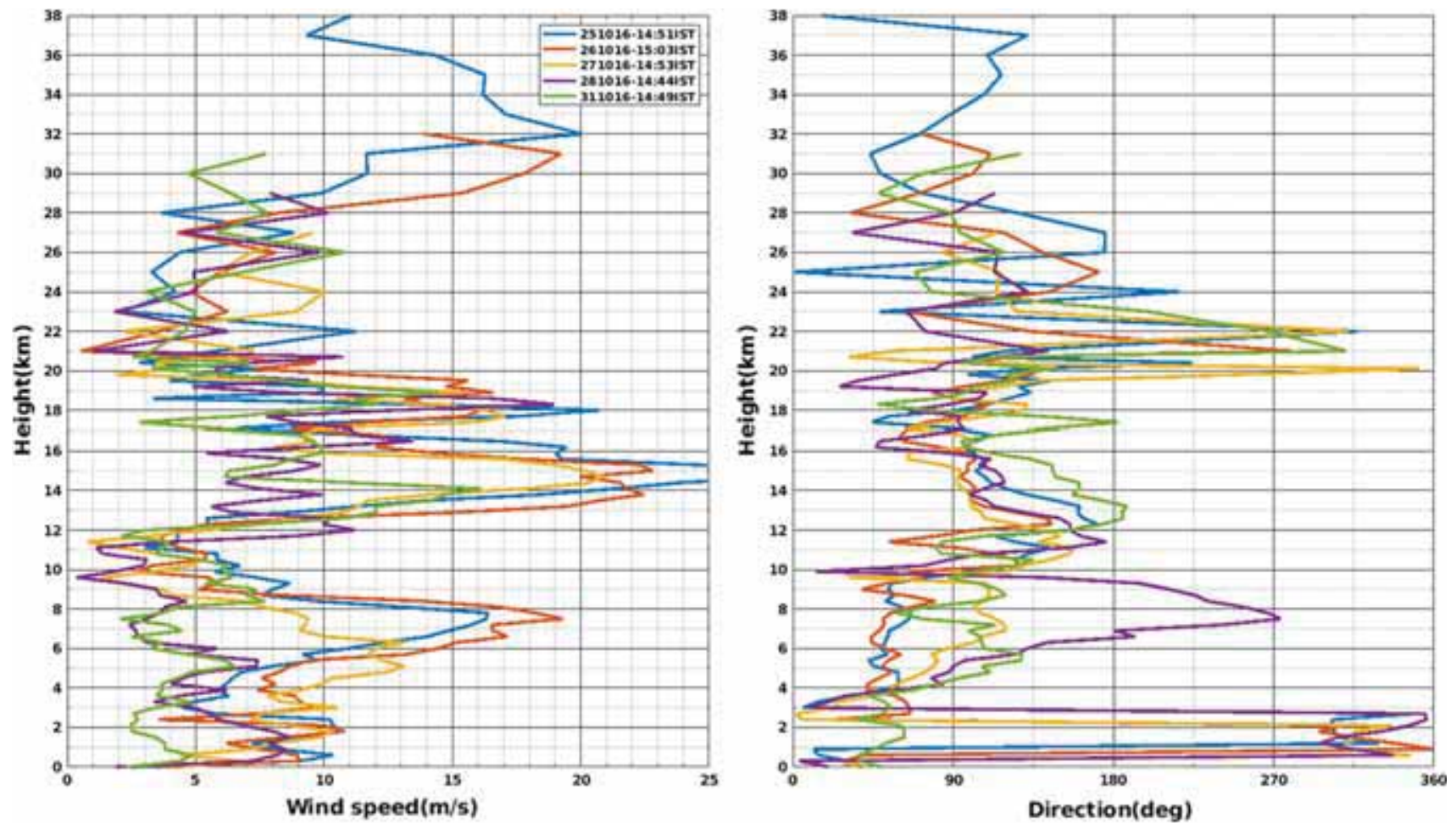

Figure 15. Wind speed and direction from GPS radiosonde with the north-easterly winds after onset for the year 2016.

(a)

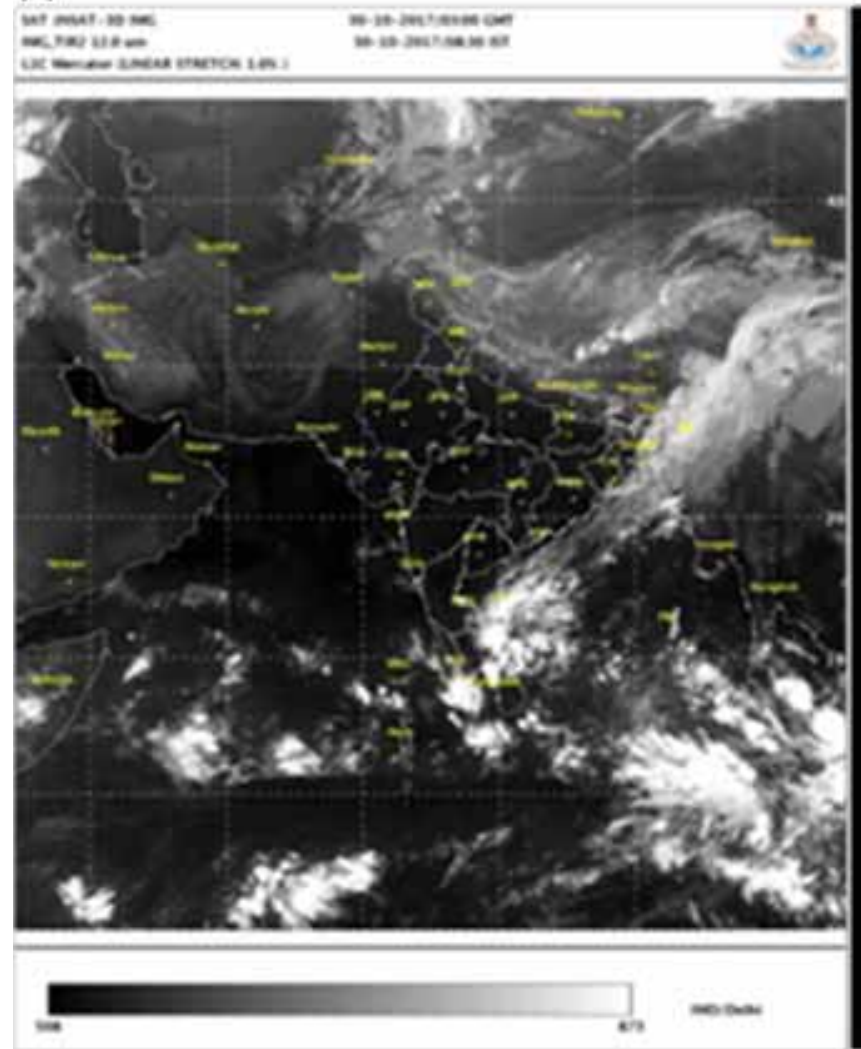

(b)

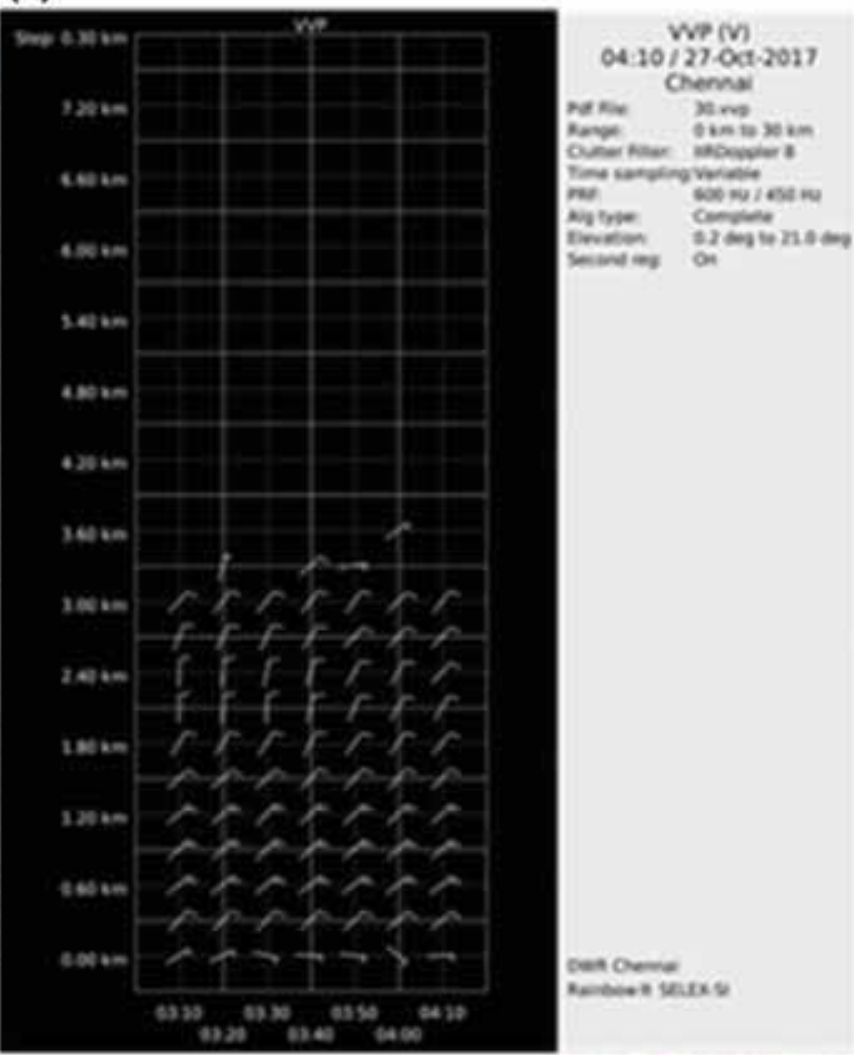

Figure 16. (a) Satellite image of a low pressure system in 2017 and (b) horizontal wind from Chennai DWR as the north-easterly winds approaching. 
(a)

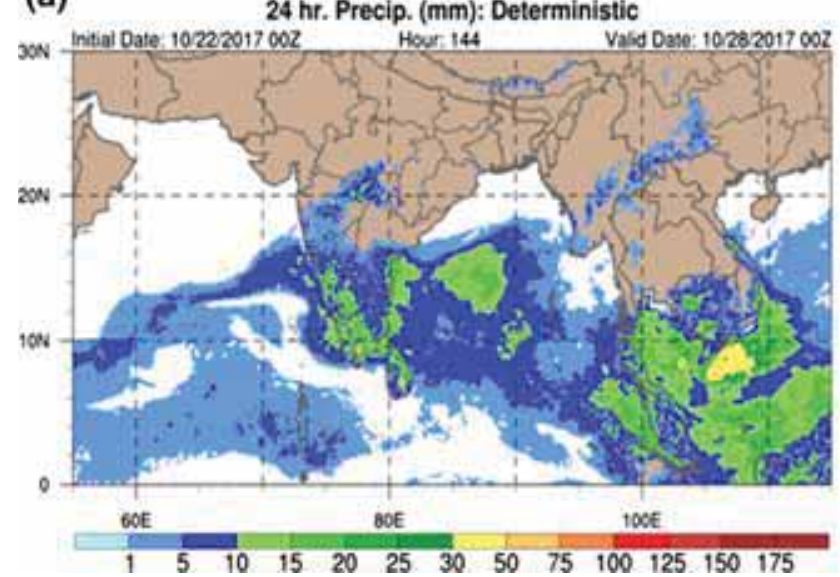

(b) $850 \mathrm{hPa}$ Relative Vorticity: Deterministic $\left(\times 10^{-5} \mathrm{~s}^{\mathrm{t}}\right)$

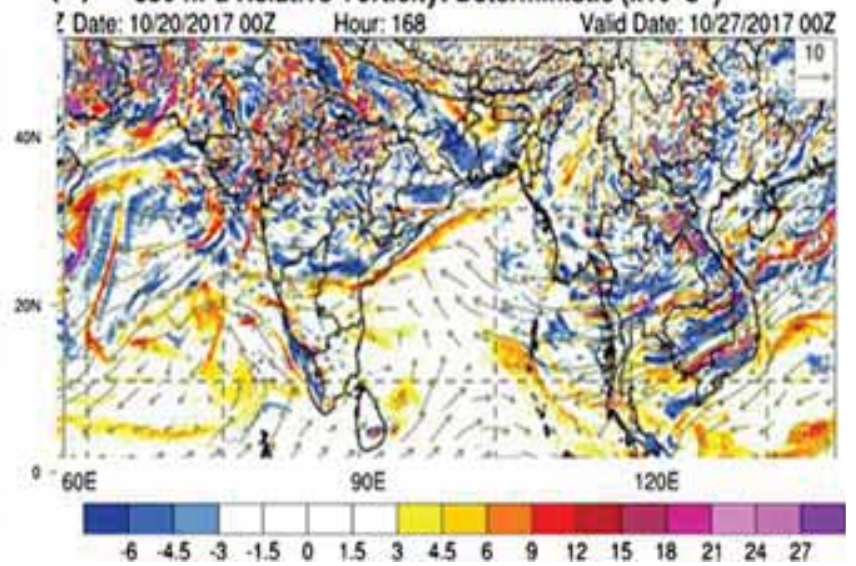

Figure 17. ECMWF model (a) deterministic precipitation based on 22 October 00 UTC initial conditions for 27 October 2017 and (b) $850 \mathrm{hPa}$ relative vorticity for 26 October 2017.
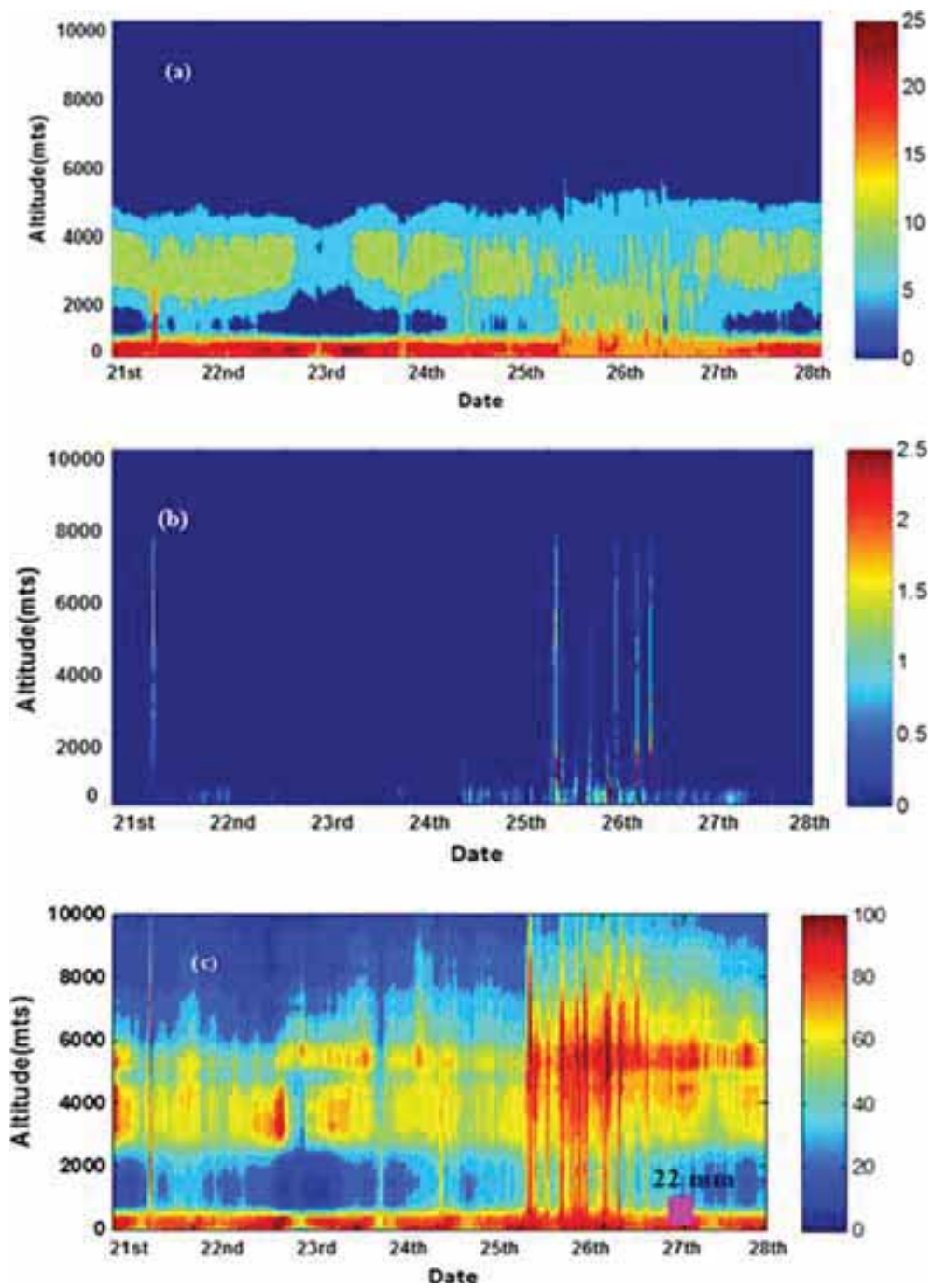

Figure 18. Time-height cross section of $(\mathbf{a})$ vapour density $\left(\mathrm{g} / \mathrm{m}^{3}\right),(\mathbf{b})$ liquid water $\left(\mathrm{g} / \mathrm{m}^{3}\right)$ and $(\mathbf{c})$ relative humidity $(\%)$ for the year 2017 before onset. Pink bars represent the rainfall amount observed on the particular day. The $x$-axis represents the dates of October 2017. The red line indicates the date of NEM onset. 

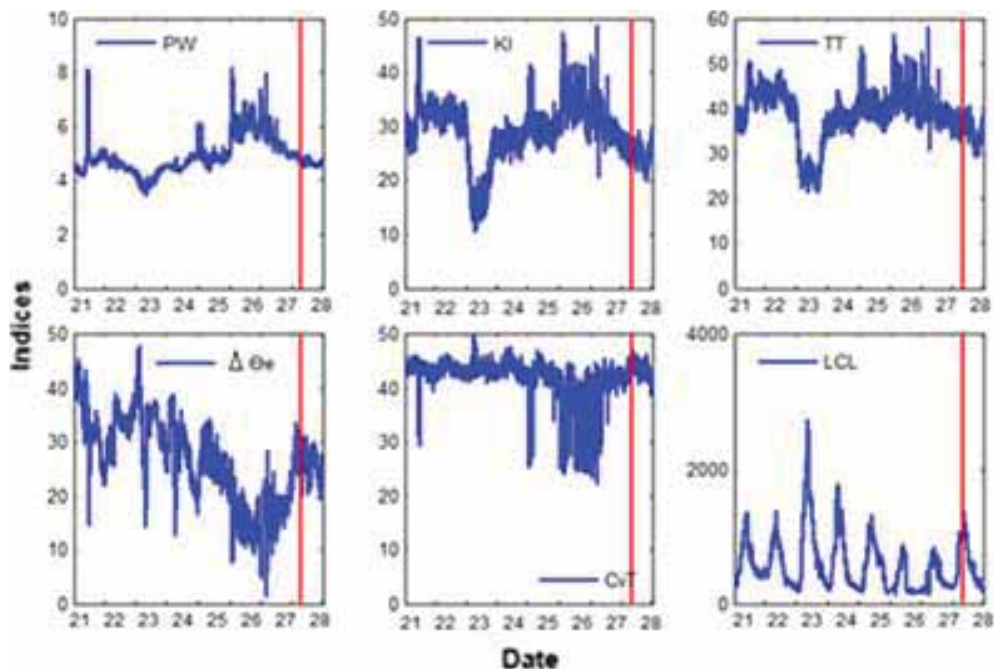

Figure 19. Thermodynamic indices variation before NEM onset for the year 2017, the red line indicates the date of onset. The $x$ axis represents the dates of October prior to onset.
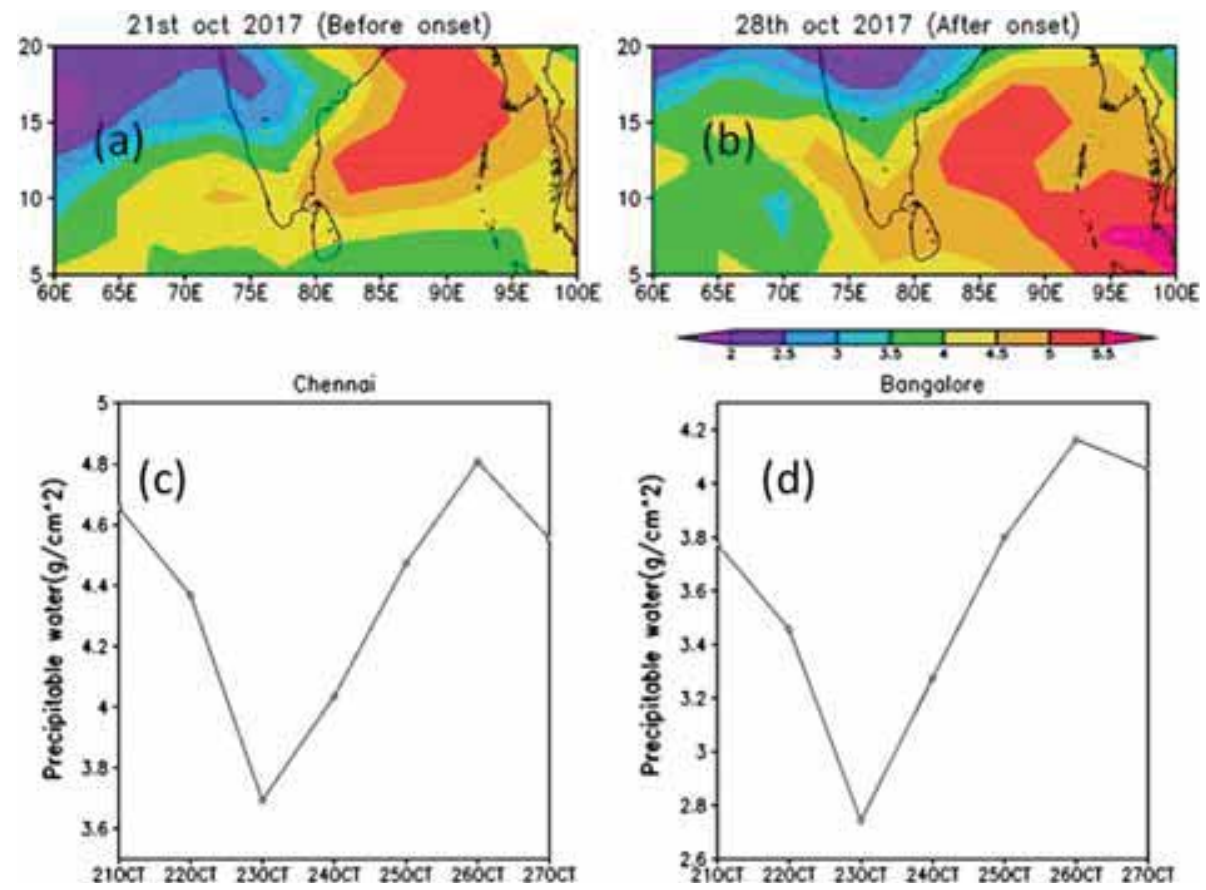

Figure 20. PW from ECMWF reanalysis for 1 week prior to onset for the year 2017: (a) before onset, (b) after onset, (c) daily PW from 21 to 27 October for Chennai and (d) the same as (c) but for Bangalore.

\subsubsection{MWR observations during 2017 NEM onset}

For the year 2017, onset rain was associated with a low pressure system. Due to the weak phase of onset, a moderate increase of vapour density and relative humidity from 25 October in low and mid-tropospheric levels is shown in figure 18.

The moist convection is controlled by factors such as radiation, LCL height, etc. Cumulus clouds are formed when the top of the entrainment zone is merged with the bottom part of LCL (Wilde et al. 1985). High values of PW in clear air often become antecedent conditions prior to the development of precipitation. Variations in thermodynamic indices were not consistent up to 25 October; later PW, KI and TT were increased and $\Delta \theta \mathrm{e}, \mathrm{LCL}$ decreased as shown in figure 19.

Daily rainfall and relative humidity prior to 1 week before onset for the year 2017 over 
SHAR are shown in figure 7(c). Rainfall occurred on 26 October with an increase of relative humidity.

Results from the ECMWF reanalysis for the year 2017 are shown in figure 20. For the south peninsular India, 1 week prior to onset, PW is in lesser amounts $\left(<4 \mathrm{~g} / \mathrm{cm}^{2}\right)$ at the southern tip of India, i.e., on 21 October 2017 (a). After the onset on 28 October 2017 (b), the PW in the same area has increased $\left(>5 \mathrm{~g} / \mathrm{cm}^{2}\right)$, resulting in an increase of moisture due to the arrival of the north-easterlies. Time series of PW variation from 21 to 27 October 2017 were plotted for Chennai and Bangalore (prone to NEM). A drastic increase of PW over Chennai is seen (c) from 3.6 to $4.8 \mathrm{~g} / \mathrm{cm}^{2}$. A slight increase in PW is seen in Bangalore (d) from 2.7 to $4.2 \mathrm{~g} / \mathrm{cm}^{2}$.

\section{Conclusions}

The primary objective of the present paper is to demonstrate the use of ground-based MWR for studying pre-NE monsoon and NEM onset features over the SHAR region for the years 2014, 2016 and 2017 in advance. This study presented co-located observations from MWR profiler and rain gauge. Basic measurement parameters from MWR like temperature and moisture profiles and derived thermodynamic indices are analysed prior to 1 week of the onset date of monsoon. In 2014, 2016 and 2017 with one early onset (2014) and one late onset (2016), 5 days advance signatures of monsoon onset are seen in terms of decreasing temperatures, increasing moisture in lower and mid-troposphere regions; however, in 2017, signatures are weak due to less moisture intrusion compared to the other 2 years. Other derived thermodynamic indices like PW, KI, TTI, $\Delta \theta \mathrm{e}, \mathrm{CT}$ and LCL have also shown 5 days early signatures of monsoon onset. Results from ECMWF reanalysis data were also well comparable with MWR observations. From the encouraging results of this study, a network of MWRs along the coastal regions may strengthen the existing observational network for monsoon onset analysis.

Furthermore, this study shows the strength of MWR for un-manned routine atmospheric observations with high temporal resolution relative to radiosonde measurements with small errors because of measurement principles. Compared to the twice-daily balloon ascents, the continuous measurements of temperature and humidity from the remote-sensing instrument give reliable data for the rapid evolution of the atmospheric thermodynamic state.

\section{Acknowledgement}

The authors would like to thank the team of SDSC SHAR for carrying out this work.

\section{References}

Anthes R A 1971 Numerical experiments with a slowly varying model of the tropical cyclone; Mon. Weather Rev. 99 636-643.

Balachandran S, Asokan R and Sridaran S 2006 Global surface temperature in relation to northeast monsoon rainfall over Tamil Nadu; J. Earth Syst. Sci. 115(3) 349-362.

Balaji B, TharaPrabha V, Jaya Rao Y, Kiran T, Dinesh G, Chakravarty K, Sonbawne S M and Rajeevan M 2017 Potential of collocated radiometer and wind profiler observations for monsoon studies; Atmos. Res. 194 17-26.

Basili P, Bonafoni S, Ferrara R, Ciotti P, Fionda E and Ambrosini R 2001 Atmospheric water vapor retrieval by means of both GPS network and microwave radiometer during an experimental campaign in Cagliari, Italy, in 1999; IEEE Trans. Geosci. Remote Sensing 39(11) 2436-2443.

Chan P W 2009 Performance and application of a multiwavelength, ground based microwave radiometer in rain nowcasting; Meteorol. Z. 18 253-265.

Dhar O N and Rakhecha P R 1983 Forecasting northeast monsoon rainfall over Tamil Nadu, India; Mon. Weather Rev. 111 109-112.

Friedrich K, Lundquist J K, Aitken M, Kalina E A and Marshall R F 2012 Stability and turbulence in the atmospheric boundary layer: A comparison of remote sensing and tower observations; Geophys. Res. Lett. 39 1-6, https://doi.org/10.1029/2011gl050413.

Galway J G 1956 The lifted index as a predictor of latent instability; Bull. Am. Meteorol. Soc. 37 528-529.

Güldner J and Spänkuch D 1999 Results of year-round remotely sensed integrated water vapor by ground-based microwave radiometry; J. Appl. Meteorol. 38 981-988.

Güldner J and Spänkuch D 2001 Remote sensing of the thermodynamic state of the atmospheric boundary layer by ground-based microwave radiometry; J. Atmos. Ocean. Technol. 18 925-933.

Kasahara A 1961 A numerical experiment on the development of a tropical cyclone; J. Meteorol. 18 259-282.

Knupp K, Ware R, Cimni D, Vandenberghe F, Vivekanandan J, Westwater E and Coleman T 2009 Ground-based passive microwave profiling during dynamic weather conditions; $J$. Atmos. Ocean. Technol. 26 1057-1072.

Kumar P, Rupa Kumar K, Rajeevan M and Sahai A K 2007 On the recent strengthening of the relationship between ENSO and northeast monsoon rainfall over South Asia; Clim. Dyn. 28(6) 649-660.

Löhnert U and Maier O 2012 Operational profiling of temperature using ground-based microwave radiometry at 
Payerne: Prospects and challenges; Atmos. Meas. Tech. 5 1121-1134, https://doi.org/10.5194/amt-5-1121-2012.

Madhulatha A, Rajeevan M, VenkatRatnam M, Bhate J and Naidu C V 2013 Nowcasting severe convective activity over South-east India using ground-based microwave radiometer observations; J. Geophys. Res., http://dx.doi.org/10.1029/ 2012JD018174.

Miller M, Buizza R, Haseler J, Mariano H, Peter J and Untch A 2010 Increased resolution in the ECMWF deterministic and ensemble prediction systems; ECMWF Newsletter Feature Article, https://www.ecmwf.int/node/17460.

Mukhopadhyay P, Sanjay J and Singh S S 2003 Objective forecast of thundery/non-thundery days using conventional indices over three northeast Indian stations; Mausam (India) $\mathbf{5 4} 867$.

Murugavel P, Malap N, Balaji B, Mehajan R K and Prabha T V 2016 Precipitable water as a predictor of LCL height; Theor. Appl. Climatol., https://doi.org/10.1007/s00704-016-1872-0.

Ooyama K 1964 A dynamical model for the study of tropical cyclone development; Geofis. Int. 4 187-189.

Pant G B and Rupa Kumar K 1997 Climates of south Asia; John Wiley \& Sons, Chichester, UK, 320p.

Pushpa Saroja R, Rajasekhar M, Paparao G, Rajeevan M and Bharathi G 2016 Assessment of forecast indices over Sriharikota using ground-based microwave radiometer; In: Proceedings of SPIE, Remote sensing of the atmosphere, clouds and precipitation VI 9876 987633, https://doi.org/ 10.1117/12.2224405.

Raj Y E A 1989 Statistical relation between winter monsoon rainfall and the preceeding summer monsoon; Mausam 41 51-56.

Corresponding editor: KaviRAJAN RAJENDRAN.
Raj Y E A and Jamadar S M 1990 Normal dates of onset and withdrawal of southwest and northeast monsoons over south peninsular India; Vayu Mandal 2076.

Raj Y E A 1998 A statistical technique for determination of northeast monsoon over coastal Tamil Nadu; Mausam 49(3) 309-320.

Rajeevan M, Unnikrishnan C K, Bhate J, Niranjan K and Sreekala P P 2012 Northeast monsoon over India: Variability and prediction; Meteorol. Appl. 19(2) 226-236.

Rambabu S, Pillai J S, Agarwal A and Pandithurai G 2014 Evaluation of brightness temperature from a forward model of ground-based microwave radiometer; J. Earth Syst. Sci. 123(4) 641-650.

Rao Krishna P R and Jagannathan P 1953 A study of the northeast monsoon rainfall of Tamil Nadu; Indian J. Meteorol. Geophys. 4 22-43.

Schultz P 1989 Relationships of several stability indices to convective weather events in Northeast Colorado; Wea. Forecasting 1 73-80.

Solheim F, Godwin J, Westwater E, Han Y, Keihm S, Marsh K and Ware R 1998 Radiometric profiling of temperature, water vapor, and liquid water using various inversion methods; Radiol. Sci. 33 393-404.

Suresh R and Bhatnagar A K 2004 Unusual hailstorms during May 2002 in Chennai and its suburbs - A study using data from a single Doppler weather radar; Mausam (India) $\mathbf{5 5}$ 655.

Wilde N P, Stull R B and Eloranta E W 1985 The LCL zone and cumulus onset; J. Clim. Appl. Meteorol., https://doi.org/ 10.1175/1520-0450(1985)024\%3c0640:tlzaco\%3e2.0.co;2. 